\title{
EVOLUÇÃO DA VASSOURA-DE-BRUXA E AVALIAÇÃO DA RESISTÊNCIA EM PROGÊNIES DE CUPUAÇUZEIRO ${ }^{1}$
}

\author{
RAFAEL MOYSÉS ALVES², MARCOS DEON VILELA DE RESENDE ${ }^{3}$, \\ BRUNA DOS SANTOS BANDEIRA ${ }^{4}$, THIAGO MARTINS PINHEIRO 5 , \\ DANIELLA CRISTINA RAIOL FARIAS ${ }^{6}$
}

RESUMO- Com o objetivo de conhecer a evolução da doença vassoura-de-bruxa, a taxa de segregação e estimar parâmetros genéticos, foi conduzido um experimento com 21 progênies de irmãos completos de cupuaçuzeiro, instalado em Belém, Pará. As progênies foram obtidas pelo cruzamento controlado de clones resistentes com clones resistentes, clones resistentes com clones suscetíveis e, clones suscetíveis com clones suscetíveis. Foram avaliadas também três progênies de meios-irmãos como testemunhas. Os experimentos foram avaliados ao nível de indivíduos, e as análises foram conduzidas via metodologia de modelos lineares mistos (procedimento REML/BLUP), como delineamento em blocos incompletos desbalanceados, com tratamentos comuns entre dois experimentos. As variáveis avaliadas foram: percentagem de plantas resistentes ao ataque da doença no ramo, inflorescência, fruto imaturo e maduro, no período de 2002 a 2007 . Os resultados mostraram que a emissão de vassoura vegetativa é especialmente importante entre julho e setembro. A evolução da doença evidencia que as podas fitossanitárias devem ser realizadas no final da safra, nos meses de maio/junho, e repassadas em setembro/outubro. A população estudada oferece excelente possibilidade de seleção e ganho genético, respaldada pelos elevados índices de variabilidade genética e herdabilidade dos caracteres de resistência. As progênies segregaram tanto para os sintomas de vassoura nos ramos, nas inflorescências, como nos frutos imaturos e maduros. Para o controle integrado desta doença, os resultados mostram a importância da associação de materiais genéticos resistentes ou moderadamente resistentes à vassoura-de-bruxa com as podas fitossanitárias.

Termos para indexação: Vassoura-de-bruxa; resistência; segregação; Theobroma grandiflorum.

\section{EVOLUTION OF THE WITCH'S BROOM DISEASE AND EVALUATION OF RESISTANCE IN CUPUASSU PROGENIES}

\begin{abstract}
This paper aimed to study the evolution and individual segregation of the witch's broom disease and estimate the genetic parameters in trials with 21 full sib families of Cupuaçú established in Belém, Pará. The progenies were obtained through control pollination involving resistant and susceptible parents in all three combinations. Three half-sib families were also evaluated as checks. The experiments were evaluated at individual level and all the analyses were based on the mixed model methodology (REML/ BLUP procedure) with unbalanced incomplete blocks design and common checks across trials. The evaluated traits comprised the percentage of resistant plants concerning the disease on the branches, on the flowers and on the mature and immature fruits from 2002 to 2007. The results showed that the disease is especially important between July and September. The disease evolution showed that pruning against the disease must be conducted at the end of the productive season in May/June and also in September/October. The breeding population can be successfully improved due to the high levels of genetic variability and heritability associated to the resistance traits. There were genetic segregations for all the traits. The integrated control of the disease, associating resistant genotypes and pruning is recommended.
\end{abstract}

Index terms: Witch's broom disease; resistance, segregation; Theobroma grandiflorum.

\footnotetext{
(Trabalho 247-08). Recebido em: 29-09-2008. Aceito para publicação em: 17-04-2009. Suporte financeiro: Embrapa e CNPq

2Doutor, Embrapa Amazônia Oriental; rafael@cpatu.embrapa.br

${ }^{3}$ Doutor, Embrapa Florestas; marcos.deon@gmail.com

${ }^{4}$ Engenheira Agrônoma - Universidade Federal Rural da Amazônia; bruban6@hotmail.com

${ }^{5}$ Graduando - Universidade Federal Rural da Amazônia, Bolsista CNPq; thiago mpinheiro@yahoo.com.br

${ }^{6}$ Graduanda - Universidade Federal Rural da Amazônia, Bolsista CNPq; daniellaraiolfarias@yahoo.com.br
} 


\section{INTRODUÇÃO}

A vassoura-de-bruxa, Crinipellis (Moniliophthora) perniciosa (Stahel), é a doença que mais ameaça os plantios de cupuaçuzeiro, Theobroma grandiflorum (Willd. ex Spreng.) Schum., na Região Amazônica. Encontra-se disseminada, de forma endêmica, em toda a região tropical da América do Sul (Purdy \& Schmidt, 1996). Com a transição da atividade extrativista para o cultivo do cupuaçuzeiro e o consequente aumento da área plantada, começaram a ser observados surtos epidêmicos da doença (Alves et al., 1998a; Alves, 1999; Alves,2003).

A doença é relativamente fácil de ser diagnosticada devido aos sintomas muito característicos nas folhas, ramos, flores e frutos. $\mathrm{O}$ ataque ocorre em regiões meristemáticas, como gemas axilares e apicais, promovendo hipertrofia, com brotações vegetativas deformadas e entrenós curtos as quais, após um mês, secam, interferindo significativamente na área fotossintética da planta. $\mathrm{O}$ ataque também ocorre em almofadas florais, que evoluem para agrupamentos de flores com tamanhos anormais, que secam precocemente, porém ficam aderidas à planta. Pequenos frutos podem aparecer na extremidade dos pedúnculos, que ficam alongados e quebradiços. $\mathrm{O}$ ataque em frutos jovens promove formação anormal, endurecimento, parada de crescimento e mumificação, que não chegam à maturidade e ficam aderidos à planta por longo tempo. Quando a infecção dos frutos é tardia, próximo da abscisão, a maturação pode ser completada, porém polpa e sementes ficam comprometidas. A disseminação da doença ocorre através dos basidiósporos, que são veiculados pelo vento e água da chuva até os sítios de infecção (Venturieri, 1993; Benchimol, 2000). O período de incubação varia de três a quatro semanas (Nunes et al., 1996), enquanto, no cacaueiro, é mais demorado, de quatro a seis semanas (Venturieri, 1993).

No Estado do Pará, grande parte dos plantios de cupuaçuzeiro encontra-se seriamente prejudicada, alguns em estado de abandono, pois utilizaram materiais genéticos suscetíveis a essa doença (Alves et al., 1998b). No cacaueiro, foram observadas perdas de até $90 \%$ da produção, em decorrência do ataque de vassoura-de-bruxa (Evans, 1981; Evans \& Bastos, 1981; Andebrhan et al., 1998).

Em razão do impacto econômico provocado por essa doença, diferentes métodos de controle têm sido tentados, tanto em cupuaçuzeiro como em cacaueiro, porém com resultados parcialmente efetivos, e sempre com aumento dos custos de produção, tornando-se, na maioria das vezes, antieconômicos
(Yoneyama et al., 1997; Rios-Ruiz, 2001).

Dentre os métodos de controle da doença, o emprego de materiais geneticamente resistentes passou a ser o mais promissor. (Alves \& Cruz, 2003; Alves et al., 2003). (Rios-Ruiz, 2001) reporta que também no cacaueiro essa estratégia é a mais interessante por ser a mais econômica, estável e ambientalmente desejável.

Para identificar a resistência genética de materiais, os testes de campo são imprescindíveis, apesar de demandarem áreas extensas e longos períodos de avaliação, bem como apresentarem dificuldade de interpretação dos resultados (Rios-Ruiz, 2001). Por outro lado, dão bons resultados em termos de resistência e suscetibilidade (Fonseca et al., 1999; Pires et al., 1999), quando se faz um bom controle das influências ambientais.

As avaliações de resistência podem ser realizadas nos diferentes órgãos da planta que são afetados pela doença. Fonseca et al. (1984) e Andebrhan (1998) reportam que em cacaueiro a resistência das partes vegetativas é, epidemiologicamente, mais importante que a resistência de almofadas florais ou frutos.

Este trabalho teve por objetivo verificar a evolução da ocorrência de vassoura-de-bruxa, a taxa de segregação, bem como estimar parâmetros genéticos em um experimento de progênies de irmãos completos de cupuaçuzeiro, instalado em Belém, Pará, visando a obter informações importantes para o melhoramento genético do cupuaçuzeiro e para o controle integrado da doença.

\section{MATERIAL E MÉTODOS}

A instalação dos experimentos aconteceu em fevereiro de 1998, na Base Física da Embrapa Amazônia Oriental, em Belém - Pará ( $1^{\circ} 28^{\prime} 00^{\prime}$ 'S e $\left.48^{\circ} 27^{\prime} 00^{\prime \prime} \mathrm{W}\right)$, que se caracteriza por clima Afi, com temperatura média elevada $\left(25,9^{\circ} \mathrm{C}\right)$, precipitação pluviométrica intensa $(3.200 \mathrm{~mm})$ e $85 \%$ de umidade relativa.

O material genético foi constituído por 21 progênies de irmãos completos (Tabela 1), avaliadas em dois experimentos, no delineamento experimental de blocos ao acaso, com cinco plantas por parcela. No primeiro experimento, foram avaliadas 16 progênies em três repetições. No segundo experimento, avaliaram-se 13 progênies, em duas repetições. Para avaliação e remoção da variância ambiental, os dois experimentos foram conectados por oito progênies comuns a eles. Foram empregadas como testemunhas progênies de meios-irmãos dos clones 174 e 286 (resistentes) e 618 (suscetíveis). 
Para a obtenção das progênies, foram realizados cruzamentos controlados. Foram utilizados os clones resistentes: 174 (Coari), 186 (Codajas), 215 (Manacapuru), 286 (Belém) e 554. Os parentais suscetíveis foram os clones 434; 513; 620; 624 e 1074. Foram realizados três grupos de cruzamentos: clones resistentes com clones resistentes (seis progênies Grupo 1), clones resistentes com clones suscetíveis (13 progênies - Grupo 2), clones suscetíveis com clones suscetíveis (duas progênies - Grupo 3) além das progênies de meios-irmãos como testemunhas (três progênies - Grupo 4).

Para fornecer a fonte primária de inóculo, em duas extremidades da copa de cada planta, foram penduradas duas vassouras secas, com aproximadamente um ano de idade, aptas para esporulação, trazidas de outros plantios, conforme metodologia adotada por Lima \& Costa (1991). Também foram plantadas progênies suscetíveis (testemunhas), para servirem de indicador do estabelecimento da doença na área. Quinzenalmente, era feito o registro do número de vassouras vegetativas brotadas em cada planta. As quantidades mensais foram usadas para montar a série histórica (2002 a 2007) e estimar o grau de severidade da doença em cada progênie.

As vassouras emitidas eram mantidas até o desprendimento da planta, por um tempo que variou de 12 a 18 meses, para incrementar a fonte de inóculo, sendo que nenhum método de controle da doença foi empregado até 2005. A partir desse ano, foram realizadas retiradas parciais das vassouras e observado o reflexo dessa prática no incremento de vassouras novas.

Para estimar a taxa de incidência da doença em cada progênie, foram identificadas as plantas que apresentavam pelo menos uma vassoura vegetativa ou reprodutiva e presença de frutos imaturos atacados.

Para quantificar a taxa de ocorrência da doença em frutos maduros, em cada progênie foram examinados cerca de cinco frutos por planta e por safra, durante seis safras, no período de 2001 a 2007. Estimou-se a taxa de frutos sadios que, para as análises estatísticas, foram transformadas para arcossen $\sqrt{ }(\mathrm{x}+0,5) / 100$.

Os dados foram analisados, via metodologia de modelos lineares mistos (procedimento REML/ BLUP), como um delineamento em blocos incompletos desbalanceados com tratamentos comuns. Isto permitiu o ajuste para os gradientes ambientais de blocos e também a recuperação de informação genética interblocos incompletos, propiciando eficiente estimação de parâmetros e seleção. Os efeitos de blocos foram considerados como aleatórios, visando a propiciar a recuperação de informação genética interblocos.

Dessa forma, os parâmetros genéticos foram estimados via REML, e os valores genotípicos ou médias genotípicas, ajustadas de progênies, bem como os valores genéticos aditivos e genotípicos individuais foram estimados pelo procedimento BLUP, por meio do software Selegen-Reml/Blup (Resende, 2002). Utilizou-se do seguinte modelo estatístico para a avaliação genética (Dias \& Resende, 2001; Resende, 2002):

$\mathrm{y}=\mathrm{Xm}+\mathrm{Zg}+\mathrm{Wb}+\mathrm{Tp}+\mathrm{e}$, em que:

$\mathrm{y}, \mathrm{m}, \mathrm{g}, \mathrm{b}, \mathrm{p}, \mathrm{e}=$ vetores de dados, de efeitos de experimento (fixos), de efeitos genotípicos de progênies de irmãos completos (aleatório), de efeitos de blocos (aleatórios), de efeitos de parcela (aleatórios) e de erros aleatórios, respectivamente.

$\mathrm{X}, \mathrm{Z}, \mathrm{W}, \mathrm{T}=$ matrizes de incidência para $\mathrm{m}$, $\mathrm{g}, \mathrm{b}$ e $\mathrm{p}$, respectivamente.

Foram realizadas estimativas de parâmetros genéticos para resistência à vassoura-de-bruxa no ramo, inflorescência, fruto imaturo e maduro, nas progênies de cupuaçuzeiro, sendo estimadas herdabilidades e correlações entre as variáveis estudadas.

\section{RESULTADOS E DISCUSSÃO}

\section{Evolução da doença}

O sintoma mais visível do ataque de vassoura-de-bruxa e, portanto, mais fácil de ser diagnosticado aparece nos ramos. Os resultados observados nos seis anos de avaliações (2002-2007) encontram-se ilustrados nas Figuras 1 e 2 . As primeiras vassouras surgiram em junho/2002, isto é, cinco meses após o início das avaliações. Nesse mesmo ano, foram produzidas 241 vassouras. Já no ano seguinte, avançou para 1.074 vassouras, evoluindo para 1.381 vassouras em 2004, e praticamente duplicou em 2005, com 2.206 vassouras. Em 2006, o número de vassouras ficou praticamente estável, com cerca de 2.301, ocorrendo um leve declínio no ano seguinte.

Esses dados servem para evidenciar a rápida evolução da doença em um plantio onde não são tomadas medidas de controle. Conforme será mostrado posteriormente, nas progênies com ambos os pais resistentes, a incidência da doença foi inferior a $10 \%$ das plantas, e as demais tiveram graus variados de segregação. Essa diversidade de genótipos, certamente, ajudou a reduzir a taxa de infestação da doença na área.

Com as intervenções (retiradas de parte das vassouras) realizadas nos anos de 2005 e 2006, houve um imediato reflexo na desaceleração da velocidade 
de emissão de novas vassouras nos últimos anos, com uma diminuição no ano de 2007 para cerca de 2.000 vassouras (Figura 1), apesar de que o número de vassouras emitidas ainda se encontrava no mesmo patamar de 2005.

Quando se observa a evolução da doença ao longo do ano (Figura 2), verifica-se que a emissão de vassouras vegetativas ocorre durante todos os meses do ano, sendo mais concentrada, na maioria dos anos, nos meses de junho a setembro. A presença de lançamentos jovens no cupuaçuzeiro acontece durante a maior parte do ano, especialmente após a safra, no final do período chuvoso. Essa fenologia favorece a ocorrência da vassoura-de-bruxa, uma vez que a quantidade de vassouras emitidas está relacionada com a presença de inóculo do patógeno no ambiente, de tecidos receptivos na planta, além de fatores climáticos. Estes dados são consistentes com os encontrados por Benchimol (2000), quando avaliou os aspectos epidemiológicos da vassourade-bruxa do cupuaçuzeiro na microrregião de Belém - PA, quando também encontrou maior incidência durante os meses de julho a agosto.

Foi observada correlação negativa $(r=$ 0,5 ) entre a emissão de vassouras vegetativas e a precipitação pluviométrica (Figura 3), notando-se que há uma tendência de aumento da emissão de vassouras vegetativas durantes os meses em que ocorre redução dos níveis de precipitação pluviométrica. Como o período de incubação varia de três a quatro semanas (Nunes et al., 1996), a infecção das gemas meristemáticas deve ter ocorrido no mês imediatamente anterior, quando a umidade relativa ainda estava muito elevada. Portanto, a poda e a eliminação das vassouras vegetativas, das almofadas florais e frutos atacados deverão ser realizadas, preferencialmente, assim que apareçam. Porém, como essa prática aumenta muito os custos de produção, deverá ser realizada, impreterivelmente, assim que terminar a safra, antes que ocorra a disseminação dos esporos do fungo, que acontece na fase de transição do período chuvoso para o período seco. A poda de condução das plantas também deverá ser realizada no mesmo período da poda fitossanitária, para evitar que haja estímulo de novas brotações no período mais favorável à doença. Assim, será minimizada a reinfecção das plantas. Como garantia, novo repasse deverá ser realizado três meses depois, conforme recomendado por Benchimol (2000).

\section{Segregação das progênies para resistência à vassoura-de-bruxa}

Observou-se segregação nas progênies tanto para os sintomas de vassoura nos ramos, nas inflorescências, como nos frutos imaturos e maduros (Tabela 1).

Parentais comprovadamente resistentes para vassoura nos ramos, como 174 (Coari), 186 (Codajas), 215 (Manacapuru) e 286 (Belém), quando cruzados entre si, ou cruzados com clones suscetíveis, segregaram com taxas variáveis, dependendo do cruzamento e do órgão da planta analisado. Em cacaueiro, RiosRuiz (2001) observou resultados semelhantes.

\section{Vassoura-de-bruxa no ramo}

Conforme é possível constatar na Tabela 1, nenhuma progênie deixou de segregar para o caráter de resistência ao ataque de vassoura-de-bruxa nos ramos, isto é, nenhuma progênie apresentou $100 \%$ das plantas livres da doença. Nos cruzamentos envolvendo ambos os parentais resistentes (Grupo 1), houve uma taxa média de $91 \%$ de plantas com resistência nos ramos. A presença de plantas suscetíveis denota que os lócus que controlam o caráter de resistência não estão em homozigose, o que já era esperado para uma espécie essencialmente pan-mítica como o cupuaçuzeiro (Alves et al., 1997).

Nos cruzamentos envolvendo clones resistentes e suscetíveis (Grupo 2), a taxa média de resistência foi de 58\%. Esse Grupo, estatisticamente, não difere do anterior, pelo teste de Tukey, ao nível de significância de $5 \%$, porém cerca de $70 \%$ das progênies também não diferem do grupo formado pelo cruzamento entre clones suscetíveis. As taxas de resistência das progênies foram muito variáveis e dependem dos parentais envolvidos.

Nas progênies onde ambos os parentais eram suscetíveis (Grupo 3), praticamente todas as plantas foram afetadas por vassoura nos ramos. Essa é, possivelmente, a situação da maioria dos plantios existentes na Amazônia, cujas mudas foram produzidas sem a preocupação com a resistência genética à doença.

As progênies-testemunha (Grupo 4) tiveram um comportamento muito semelhante àquelas do Grupo 2. Este resultado era esperado, pois como se trata de progênies de meios-irmãos, onde apesar de os parentais femininos serem resistentes, o pólen provavelmente foi originado de clones suscetíveis que se encontravam na circunvizinhança.

Os resultados aqui apresentados revelaram que, regra geral, em todos os grupos de que participou o clone 186 (Codajas), é o que confere as maiores taxas nominais de resistência aos seus descendentes, revelando-se como excelente parental para cruzamentos.

Por outro lado, ficou demonstrado o risco que 
representa utilizar sementes de clones resistentes de quadras não isoladas, pois darão origem acerca de $40 \%$ de plantas suscetíveis ou, o que é mais drástico, no caso de as matrizes não serem resistentes, serão esperadoas praticamente $100 \%$ das plantas sensíveis à doença nos ramos.

Os resultados da gradação de resistência também indicaram que esta é complexa, provavelmente, do tipo poligênica, cujos lócus se encontram em alto grau de heterozigosidade. Como não são realizadas inoculações artificiais com uma raça específica do patógeno, ocorre, ao nível de campo, a manifestação de resistência horizontal. Para que seja possível estimar a natureza genética da resistência observada, há necessidade de realizar experimentos específicos, com maior número de cruzamentos e maior número de indivíduos por cruzamento.

\section{Vassoura-de-bruxa na inflorescência}

O resultado da resistência das progênies à vassoura-de-bruxa na inflorescência (Tabela 1) apresenta um padrão médio semelhante ao ataque nos ramos. Entretanto, foi possível observar que a severidade de ataque foi mais marcante nos ramos que nas inflorescências. $\mathrm{O}$ grande diferencial foi à presença de progênies com todas as plantas livres da doença. No Grupo 1, a exceção da progênie 4, todas as demais apresentaram $100 \%$ das plantas resistentes. E no Grupo 2, as progênies 12; 20 e 24 tiveram esse mesmo desempenho. Os genitores desses cruzamentos são, provavelmente, heterozigotos complementares.

Estatisticamente, é possível distinguir dois grupos: o formado pelas progênies que possuem os dois parentais suscetíveis (progênies 10 e 22), em que $74 \%$ das plantas apresentaram sintomas da doença, e o outro grupo formado pelas progênies que possuem os dois parentais resistentes, com apenas 3\% das plantas afetadas.

Por outro lado, não há condições de separar, estatisticamente, os grupos resistente $\mathrm{x}$ resistente, do grupo resistente $\mathrm{x}$ suscetível, apesar de as seis progênies do primeiro $(1 ; 2 ; 4 ; 7 ; 13$ e 14) apresentarem taxa média de segregação de apenas $3 \%$, contra $33 \%$ de segregação média do segundo grupo. Excetuamse as progênies 5 e 17, que foram estatisticamente diferentes daquelas do primeiro grupo.

\section{Vassoura-de-bruxa no fruto imaturo}

Esta variável está intimamente relacionada com o ataque na inflorescência. Isto é, inflorescências atacadas (almofadas florais) originam frutos que apre- sentam um desenvolvimento totalmente anormal, na forma de cenoura ou morango, que assumem, posteriormente, uma consistência petrificada, podendo ficar presos ao ramo por até 24 meses. Essas estruturas servem para a multiplicação de basidiocarpos, aumentando a fonte de inóculo da doença. Por essa razão, devem ser retirados junto com as vassouras de ramos, por ocasião da poda fitossanitária.

Apesar de haver uma resposta ligeiramente diferenciada das progênies a essas duas variáveis, a tendência de comportamento foi muito parecida. Das seis progênies do Grupo 1, três foram afetadas levemente pela doença, que correspondeu à média de $95 \%$ de plantas resistentes. No Grupo 2, a taxa média de plantas livres da doença reduziu para $75 \%$. A progênie 20 destacou-se novamente e teve todas as suas plantas não infectadas. No Grupo 3 , a intensidade de ataque foi ainda maior e somente $40 \%$ das plantas não evidenciaram sintomas de frutos imaturos danificados por vassoura.

Quando a taxa de ataque na inflorescência for superior ao aparecimento de frutos imaturos doentes, como é o caso das taxas médias das progênies do Grupo 2 e 3, significa que parte das inflorescências atacadas cai precocemente e não evolui para frutos. Porém houve progênies, como a 2; 7; 12; e 24, que não foram atacadas nas inflorescências, mas apresentaram algum nível de ataque nos frutos imaturos. Nesse caso, a contaminação pode ter ocorrido no início do desenvolvimento do fruto. Isto sugere que o caráter vassoura-de-bruxa nos frutos imaturos é, também, importante na avaliação da resistência.

\section{Vassoura-de-bruxa nos frutos maduros}

Os grupos de progênies não diferiram estatisticamente para esta variável (Tabela 1), observandose uma segregação média de $10 ; 12 ; 20$ e $14 \%$ para os grupos 1; 2; 3 e testemunhas, respectivamente. Esses resultados sugerem que o controle genético para resistência ao ataque de vassoura nos frutos é fraco ou inexistente, se comparado com as variáveis anteriores, pois não conseguiu discriminar os diferentes cruzamentos. Assim, cruzamentos entre clones resistentes e cruzamentos entre clones suscetíveis apresentaram segregação semelhante.

\section{Estimativa de parâmetros genéticos}

Na Tabela 2, são apresentadas estimativas dos parâmetros genéticos para resistência à vassourade-bruxa.

Os caracteres de resistência apresentaram alta variabilidade genética, com coeficientes de 
variação genética variando de $23 \%$ a $41 \%$, exceto o caráter ausência de vassoura-de-bruxa nos frutos maduros ( $5 \%$ de variação genética) (Tabela 2). Isto revela excelente possibilidade para a seleção nessa população experimental híbrida.

As herdabilidades individuais foram calculadas considerando ausência de dominância ou, mais exatamente, negligenciaram $25 \%$ da variação genética de dominância que está presente na variação genotípica entre progênies. Neste caso, a herdabilidade individual, no sentido restrito, variou de $6 \%$ (nos frutos maduros) a 27\% (nas inflorescências). Herdabilidades nessas magnitudes são esperadas para os caracteres quantitativos e também está de acordo com os valores obtidos para cacau, conforme relatado por Dias \& Resende (2001).

As herdabilidades de média de progênie variaram de $60 \%$ (nos frutos maduros) a $90 \%$ (nas inflorescências), e as acurácias na seleção de progênies variaram de $78 \%$ (nos frutos maduros) a 95\% (nas inflorescências). Assim, todos os caracteres propiciam alta eficiência seletiva.

Na Tabela 3, são apresentadas estimativas de correlação genética envolvendo os quatro caracteres relacionados com a resistência à vassoura-de-bruxa, e entre estes e a produção de frutos.

As correlações genotípicas envolvendo a resistência ao ataque da vassoura-de-bruxa nos ramos, inflorescências e frutos imaturos foram positivas e de alta magnitude, ao nível de significância de 5\%, com valores de 0,86 a 0,92. Assim, qualquer desses três caracteres representa bem um ao outro. Como em campo a verificação do ataque nos ramos é mais fácil, esta deve ser sugerida nos ensaios de avaliação de resistência.

Por outro lado, as correlações com o ataque nos frutos maduros foram de menores magnitudes, mostrando novamente que o controle genético desse caráter é um pouco diferenciado. Uma possível explicação é que a sintomatologia da doença nos frutos maduros pode ser confundida com outras pragas e doenças, e como o diagnóstico da doença nos frutos maduros foi feito de forma visual, podem ter ocorrido erros de diagnóstico.

Foram observadas, também, correlações positivas entre resistência à vassoura-de-bruxa e produção de frutos (Tabela 3), sugerindo que, para essa população quanto maior a resistência da progênie, maior será seu potencial para produção de frutos.

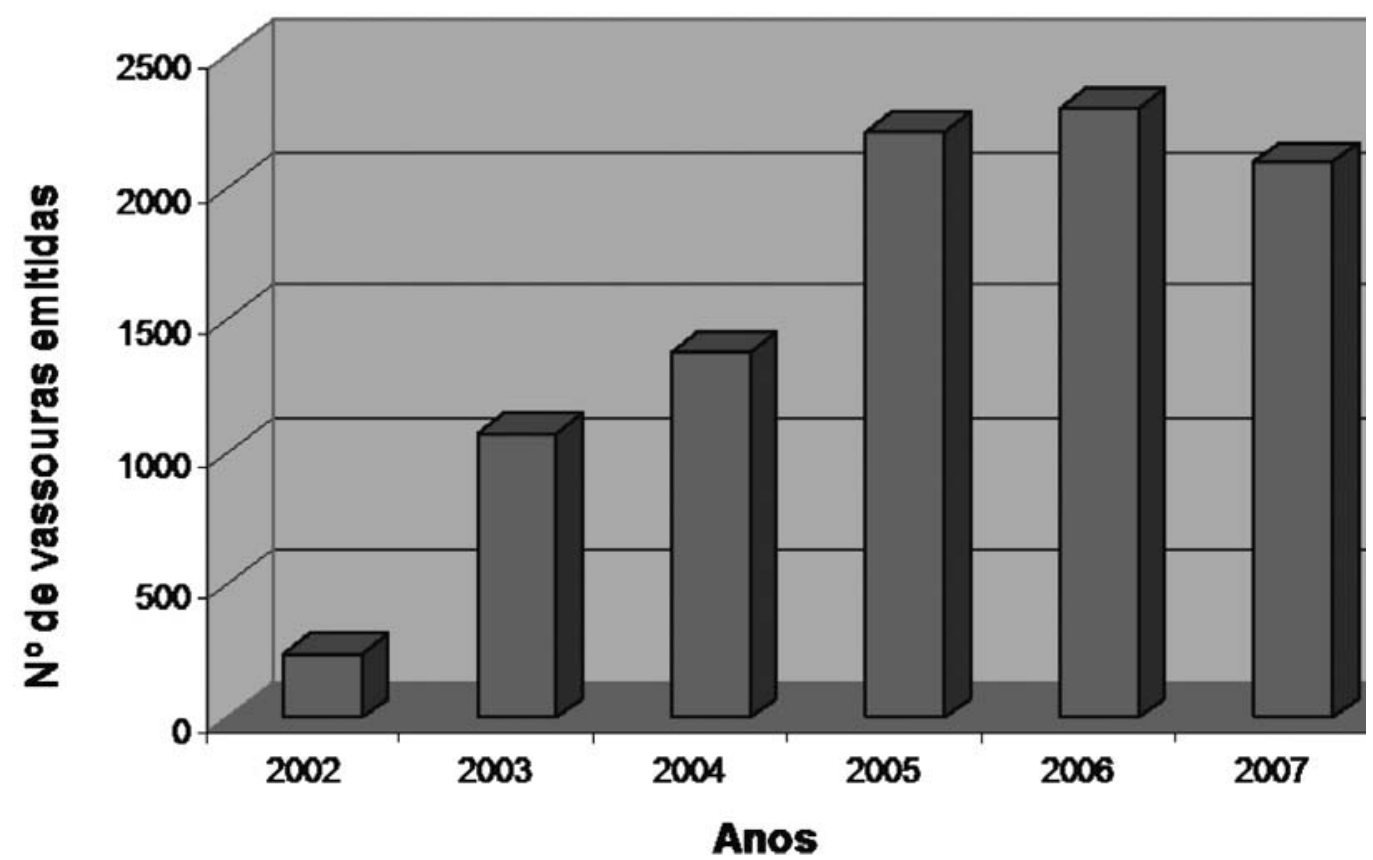

FIGURA 1 - Número de vassouras emitidas na área experimental, anualmente, entre 2002 e 2007. 
TABELA 1 - Percentagem de plantas resistentes, isto é, que não apresentaram sintomas da doença vassourade-bruxa nos ramos, inflorescências, frutos imaturos e frutos maduros, no experimento de progênies de cupuaçuzeiro, em Belém - Pará, 2008.

\begin{tabular}{|c|c|c|c|c|c|}
\hline Código & Parentais & $\begin{array}{c}\mathrm{R} \text { a } \mathrm{m} \text { o s } \\
(\%)\end{array}$ & $\begin{array}{c}\text { Inflorescência } \\
(\%)\end{array}$ & $\begin{array}{c}\text { Frutos Imaturos } \\
(\%)\end{array}$ & $\begin{array}{c}\text { Frutos Maduros } \\
(\%)\end{array}$ \\
\hline \multicolumn{6}{|c|}{ Resistentes x Resistentes } \\
\hline 1 & $174 \times 186$ & $93.33 \mathrm{a}$ & $100.00 \mathrm{a}$ & $100.00 \mathrm{a}$ & $92.67 \mathrm{a}$ \\
\hline 2 & $174 \times 286$ & $96.00 \mathrm{a}$ & $100.00 \mathrm{a}$ & $92.00 \mathrm{ab}$ & $97.19 \mathrm{a}$ \\
\hline 4 & $174 \times 554$ & $84.00 \mathrm{a}$ & $84.00 \mathrm{ab}$ & $84.00 \mathrm{ab}$ & $92.73 \mathrm{a}$ \\
\hline 7 & $186 \times 554$ & $87.00 \mathrm{a}$ & $100.00 \mathrm{a}$ & $92.00 \mathrm{ab}$ & $85.98 \mathrm{a}$ \\
\hline 13 & $186 \times 215$ & $93.33 \mathrm{a}$ & $100.00 \mathrm{a}$ & $100.00 \mathrm{a}$ & $85.99 \mathrm{a}$ \\
\hline 14 & $215 \times 286$ & $93.33 \mathrm{a}$ & $100.00 \mathrm{a}$ & $100.00 \mathrm{a}$ & $85.24 \mathrm{a}$ \\
\hline Média & & 91,20 & 97,30 & 94,70 & 90,00 \\
\hline \multicolumn{6}{|c|}{ Grupo 2 Resistentes x Suscetíveis } \\
\hline 3 & $174 \times 513$ & $46.67 \mathrm{abc}$ & $66.67 \mathrm{abc}$ & $86.67 \mathrm{ab}$ & $89.87 \mathrm{a}$ \\
\hline 5 & $174 \times 620$ & $43.34 \mathrm{abc}$ & $43.34 \mathrm{bc}$ & $73.34 \mathrm{ab}$ & $89.51 \mathrm{a}$ \\
\hline 6 & $174 \times 624$ & $60.00 \mathrm{abc}$ & $63.33 \mathrm{abc}$ & $93.33 \mathrm{a}$ & $92.52 \mathrm{a}$ \\
\hline 8 & $554 \times 434$ & $48.00 \mathrm{abc}$ & $58.00 \mathrm{abc}$ & $58.00 \mathrm{ab}$ & $81.47 \mathrm{a}$ \\
\hline 12 & $186 \times 434$ & $80.00 \mathrm{a}$ & $100.00 \mathrm{a}$ & $80.00 \mathrm{ab}$ & $87.28 \mathrm{a}$ \\
\hline 15 & $174 \times 434$ & $73.33 \mathrm{a}$ & $66.67 \mathrm{abc}$ & $80.00 \mathrm{ab}$ & $92.71 \mathrm{a}$ \\
\hline 17 & $554 \times 624$ & $32.50 \mathrm{abc}$ & $32.50 \mathrm{bc}$ & $42.50 \mathrm{ab}$ & $81.45 \mathrm{a}$ \\
\hline 18 & $186 \times 1074$ & $90.00 \mathrm{a}$ & $80.00 \mathrm{ab}$ & $87.50 \mathrm{ab}$ & $91.17 \mathrm{a}$ \\
\hline 19 & $554 \times 1074$ & $40.00 \mathrm{abc}$ & $53.33 \mathrm{abc}$ & $60.00 \mathrm{ab}$ & $89.51 \mathrm{a}$ \\
\hline 20 & $186 \times 513$ & $90.00 \mathrm{a}$ & $100.00 \mathrm{a}$ & $100.00 \mathrm{a}$ & $94.71 \mathrm{a}$ \\
\hline 21 & $215 \times 624$ & $48.00 \mathrm{abc}$ & $60.00 \mathrm{abc}$ & $84.00 \mathrm{ab}$ & $91.63 \mathrm{a}$ \\
\hline 23 & $554 \times 620$ & $46.67 \mathrm{abc}$ & $53.33 \mathrm{abc}$ & $46.67 \mathrm{ab}$ & $77.14 \mathrm{a}$ \\
\hline 24 & $286 \times 513$ & $60.00 \mathrm{abc}$ & $100.00 \mathrm{a}$ & $90.00 \mathrm{ab}$ & $88.00 \mathrm{a}$ \\
\hline Média & & 58,35 & 67,47 & 75,54 & 88,23 \\
\hline \multicolumn{6}{|c|}{ Grupo 3 Suscetíveis x Suscetíveis } \\
\hline 10 & $434 \times 1074$ & $0.00 \mathrm{c}$ & $12.00 \mathrm{c}$ & $32.00 \mathrm{~b}$ & $75.49 \mathrm{a}$ \\
\hline 22 & $434 \times 513$ & $6.67 \mathrm{bc}$ & $40.00 \mathrm{bc}$ & $46.67 \mathrm{ab}$ & $83.58 \mathrm{a}$ \\
\hline Média & & 3,34 & 26,00 & 39,34 & 79,54 \\
\hline \multicolumn{6}{|c|}{ Grupo $4 \quad$ Testemunha } \\
\hline 174 & Progênies meios-irmãos & $40.00 \mathrm{abc}$ & $40.00 \mathrm{bc}$ & $50.00 \mathrm{ab}$ & $87.46 \mathrm{a}$ \\
\hline 286 & Progênies meios-irmãos & $86.67 \mathrm{a}$ & $86.67 \mathrm{ab}$ & $86.67 \mathrm{ab}$ & $94.3 \mathrm{a}$ \\
\hline 186 & Progênies meios-irmãos & $70.00 \mathrm{ab}$ & $80.00 \mathrm{ab}$ & $70.00 \mathrm{ab}$ & $77.34 \mathrm{a}$ \\
\hline \multicolumn{2}{|l|}{ Média } & 65,56 & 68,89 & 68,89 & 86,37 \\
\hline & $\mathrm{CV}(\%)$ & 31,94 & 24,48 & 24,92 & 19,55 \\
\hline
\end{tabular}

Médias seguidas pela mesma letra na coluna não diferem significativamente entre si, pelo teste de Tukey, a 5\% de probabilidade. 


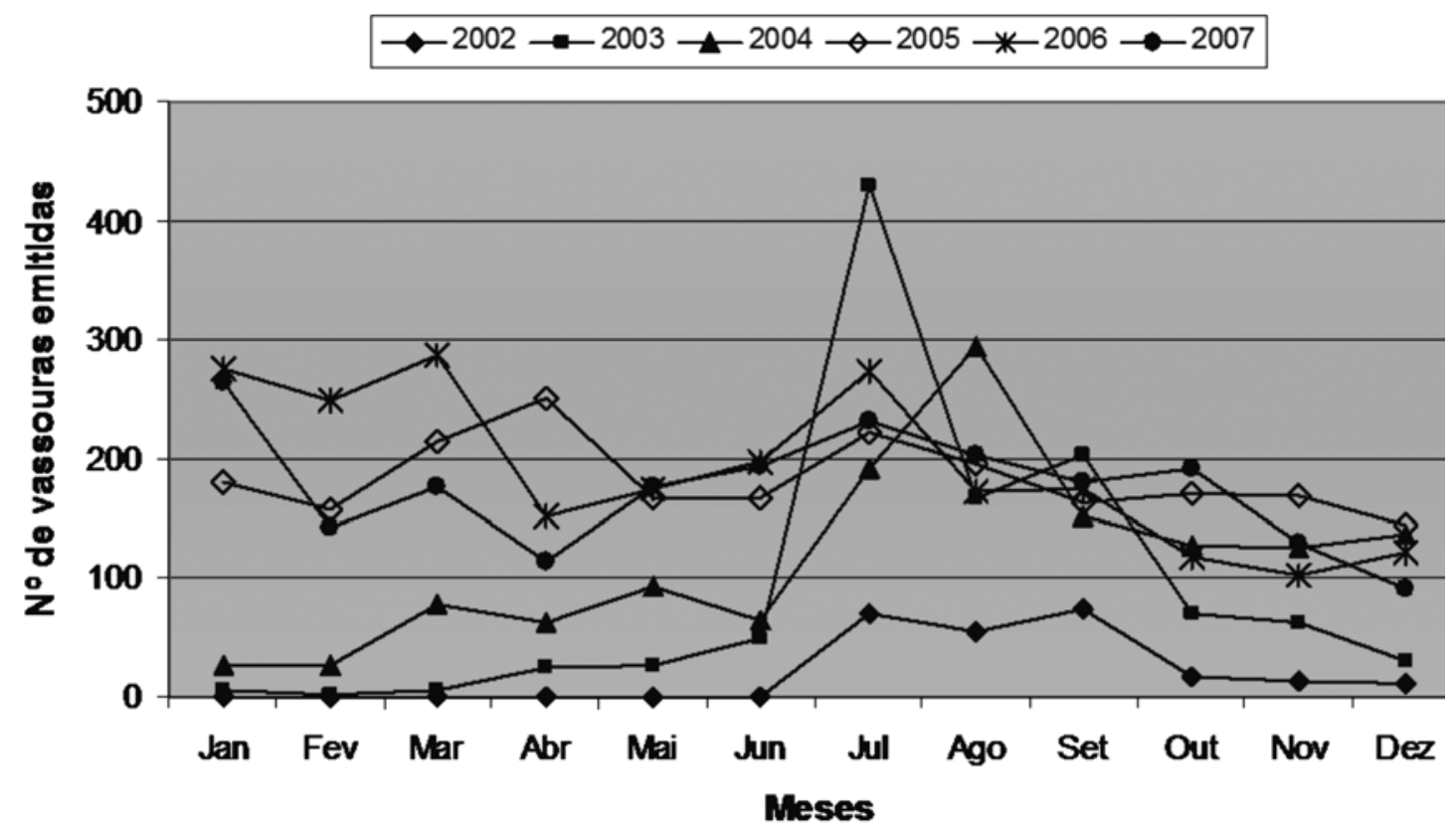

FIGURA 2 - Média mensal do número de vassouras-de-bruxa observadas entre os anos de 2002 a 2007.

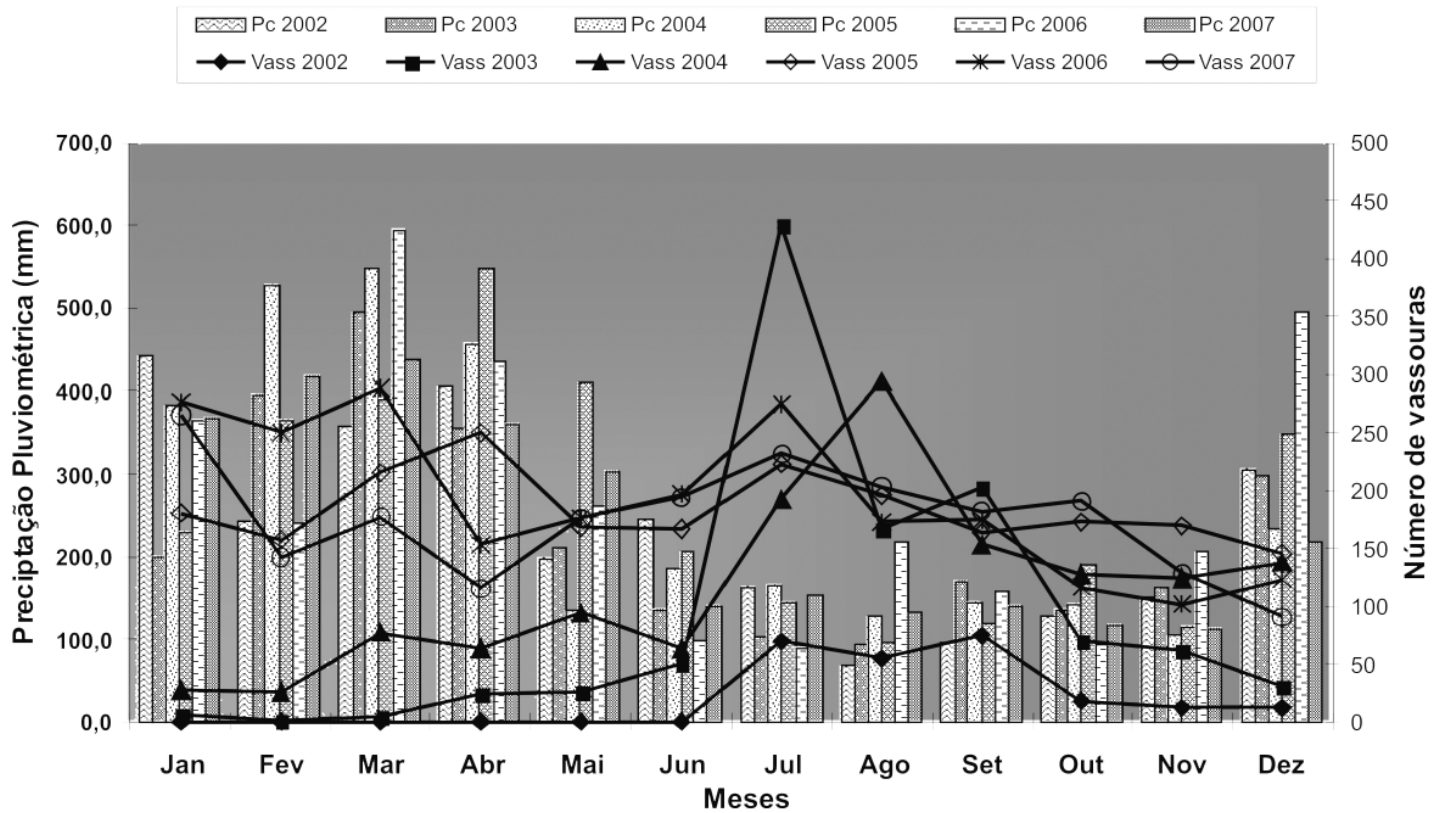

FIGURA 3 - Média mensal da precipitação pluviométrica $(\mathrm{Pc})$ e do número de vassouras-de-bruxa observadas (Vass), entre os anos de 2002 a 2007. 
TABELA 2 - Estimativas de parâmetros genéticos para resistência à vassoura-de-bruxa no ramo, inflorescência, fruto imaturo e maduro, em progênies de cupuaçuzeiro, em Belém - Pará, 2008.

\begin{tabular}{ccccc}
\hline Parâmetros & Ramo & Inflorescência & Fruto Imaturo & Fruto Maduro \\
\hline Herdabilidade individual no sentido restrito & 0.25 & 0.27 & 0.15 & 0.06 \\
Herdabilidade da média de progênies & 0.89 & 0.90 & 0.81 & 0.60 \\
Acurácia na seleção de progênies & 0.95 & 0.95 & 0.90 & 0.78 \\
Coeficiente de Variação Genética (\%) & 41.11 & 34.07 & 23.29 & 4.88 \\
Coeficiente de Variação Residual (\%) & 31.57 & 24.79 & 24.96 & 8.84 \\
\hline Média Geral & 63.01 & 71.85 & 76.64 & 87.74 \\
\hline
\end{tabular}

TABELA 3 - Estimativas de correlações genéticas entre quatro caracteres relacionados à resistência à vassoura-de-bruxa (no ramo, inflorescência, fruto imaturo e maduro), e entre estes e a produção de frutos, em progênies de polinização controlada de cupuaçuzeiro, em Belém - Pará, 2008.

\begin{tabular}{cccccc}
\hline Caracteres & Ramo & Inflorescência & Fruto Imaturo & Fruto Maduro & Produção de frutos \\
\hline Ramo & 1 & 0.9222 & 0.8647 & 0.5894 & 0,34 \\
Inflorescência & & 1 & 0.8752 & 0.5184 & 0,39 \\
Fruto Imaturo & & & 1 & 0.7053 & 0,31 \\
Fruto Maduro & & & & 1 & 0,16 \\
\hline
\end{tabular}

\section{CONCLUSÕES}

1-Apesar de a emissão de vassouras vegetativas ocorrer durante todos os meses do ano, ela é especialmente importante nos meses de julho a setembro.

2-As progênies segregaram tanto em relação aos sintomas de vassoura nos ramos e nas inflorescências, como nos frutos imaturos e maduros, indicando que os lócus responsáveis pela resistência se encontravam em heterozigose. Maiores taxas de resistência foram verificadas em progênies dos cruzamentos envolvendo clones resistentes.

3-Elevados valores de variabilidade genética e herdabilidade dos caracteres de resistência à vassoura-de-bruxa, indicaram excelente possibilidade de seleção na população estudada.

4-Nas avaliações de campo para a seleção de materiais com resistência à vassoura-de-bruxa, não existe diferença se os sintomas da doença são diagnosticados nos ramos, inflorescências ou frutos imaturos. Porém, pela facilidade de execução, deve ser preferida a contagem dos ramos atacados.

5-A utilização de material de plantação geneticamente resistente, ou moderadamente resistente, acrescida de poda das vassouras, são estratégias adequadas para o controle integrado da doença vassoura-de-bruxa.

\section{REFERÊNCIAS}

ALVES, R.M.; CORRÊA, J.R.V.; RODRIGO, M. Melhoramento genético do cupuaçuzeiro (Theobroma grandiflorum) no Estado do Pará. In: SEMINÁRIO INTERNACIONAL SOBRE PIMENTA-DO-REINO E CUPUAÇU, 1., Belém, 1996. Anais... Belém: EMBRAPA, CPATU/JICA, 1997. p.127-146. (Documentos, 88)

ALVES, R.M.; STEIN, R.L.B.; ARAÚJO, D.G. de; PIMENTEL, L. Avaliação de clones de cupuaçuzeiro quanto à resistência à vassoura-de-bruxa. Revista Brasileira de Fruticultura, Jaboticabal, v.20, n.3, p.297-306, 1998a.

ALVES, R.M.; CORRÊA, J.R.V.; GOMES, M.R.O. Avaliação preliminar de matrizes de cupuaçuzeiro (Theobroma grandiflorum) em áreas de produtores de Tomé-Açu, Pará. In: ENCONTRO DE GENÉTICA DO NORDESTE, 13., 1998, Feira de Santana. Resumos... Feira de Santana: Sociedade Brasileira de Genética, Seção Nordeste, 1998b. p.359.

ALVES, R.M. Cupuaçuzeiro (Theobroma grandiflorum Willd. ex. Spreng) Schum). In: EMBRAPA. Centro de Pesquisa Agroflorestal da Amazônia Oriental. Programa de melhoramento genético e de adaptação de espécies vegetais para a Amazônia Oriental. Belém, 1999. cap.1, p.3748. (Documentos, 16) 
ALVES, R.M. Caracterização genética de populações de cupuaçuzeiro Theobroma grandiflorum (Willd.ex.Spreng.) Schum., por marcadores microssatélites e descritores botânico-agronômicos. 2003. 146 f. Tese (Doutorado) - Escola Superior de Agricultura Luis de Queiroz, Universidade de São Paulo, 2003.

ALVES, R.M.; FARIAS NETO, J. T.; CRUZ, E.D.; OLIVEIRA, M.S.P. Estratégias do melhoramento genético desenvolvido pela Embrapa Amazônia Oriental, para obtenção das primeiras cultivares de cupuaçuzeiro e açaizeiro. In: SEMINÁRIO TÉCNICO BRASIL-JAPÃO PROJETO "DESENVOLVIMENTO TECNOLÓGICO PARA A AGRICULTURA SUSTENTÁVEL NA AMAZÔNIA ORIENTAL. 2003. Anais. Belém: EMBRAPA-CPATU, 2003.

ALVES, R.M; CRUZ, E.D. Cultivares de cupuaçuzeiro tolerantes à vassoura-de-bruxa. Belém: Embrapa Amazônia Oriental, 2003. 4p. Recomendações Técnicas.

ANDEBRHAN, T.; ALMEIDA, L. C.; NAKAYAMA, H.I. Resistencia de Theobroma cacao L. a Crinipellis perniciosa (Stahel) Singer: a experiencia da Amazônia brasileira. Agrotrópica, Itabuna, v. 10, p. 49-60, 1998.

BENCHIMOL, R.L. Doenças do cupuaçuzeiro causadas por fungos. Belém: Embrapa Amazônia Oriental, 2000. p.50.

DIAS, L. A. dos S. ; RESENDE, M. D. V. Experimentação no Melhoramento. In: Luiz Antônio dos Santos Dias. (Org.). Melhoramento genético do cacaueiro. Viçosa: FUNAPE, 2001. p. 439-492.

EVANS, H. C. Witches' broom disease - a case study. Cocoa Growers' Bulletin, Bournville, v.32, p. 5-19, 1981.

EVANS, H. C.; BASTOS, C. N. Preliminary results of research on witches' broom disease of cacao (Crinipellis perniciosa), in the Amazonian region of Brazil. In: INTERNATIONAL COCOA RESEARCH CONFERENCE, 7., 1979, Duala. Proceedings... Duala: Cocoa Producer's Alliance, 1981. p. 255-256.
FONSECA, S.E.A.; ALMEIDA, L.C.; ANDEBRHAN, T. Patogenicidade de isolados e avaliação de resistência de clones de cacau a Crinipellis perniciosa. In: INTERNATIONAL COCOA RESEARCH CONFERENCE, 9., 1984, Lagos. Proceedings... Lagos: Cocoa Producers'Alliance, 1984. p. 233-236.

FONSECA, S.E.A.; FRANCISCO NETO, E.; ALBUQUERQUE, P.S.B.; ALMEIDA, C.M.V. C. A contribuição das pesquisas na Amazônia brasileira para resistência do cacaueiro às doenças. In: INTERNATIONAL WORKSHOP ON THE CONTRIBUTION OF DISEASE RESISTANCE TO COCOA VARIETY IMPROVEMENT, 1999. Reading. Proceedings... p. 103-105.

LIMA, R.R.; COSTA, J.P.C. da. Registro de introduções de plantas de cultura précolombiana coletadas na Amazônia Brasileira. Belém: EMBRAPA, CPATU, 1991. 191p. (Série Documentos, 58).

NUNES, A.M.L.; ALBUQUERQUE, F.C.; OLIVEIRA, R.P.; SÁ, T.D.A.; NUNES, M.A.L.; SHIMIZU, O. Epidemiologia da vassoura-debruxa do cupuaçuzeiro. In: EMBRAPA. Centro de Pesquisa Agroflorestal da Amazônia Oriental. Geração de tecnologia agroindustrial para o desenvolvimento do trópico úmido. Belém, 1996. p.83-105. (Documentos, 85).

PIRES, J.L.; MONTEIRO, W.R.; LUZ, E.D.M.N.; SILVA， S.D.V.M.; PINTO， L.R.M.; FIGUEIRA, A.; GRAMACHO, K.P.; LOPES, U.V.; ALBUQUERQUE, P.S.B.; YAMADA, M. M.; AHNERT, D.E.; BRUGNEROTTO, M. I. B.; Cocoa breeding for Witches' broom resistance at CEPEC, Bahia, Brazil. In: INTERNATIONAL WORKSHOP ON THE CONTRIBUTION OF DISEASE RESISTANCE TO COCOA VARIETY IMPROVEMENT, 1999, Reading. Proceedings.... p. 91-101.

PURDY, L. H.; SCHMIDT, R.A. Status of cacao witches' broom: biology, epidemiology and management. Annual Review Phytopathology. Wardowsky, v.34, p.573-94, 1996.

RESENDE, M. D. V. de.. Genética biométrica e estatística no melhoramento de plantas perenes. Brasília: Embrapa Informação Tecnológica, 2002. p. 975 . 
RIOS-RUIZ, R.A. Melhoramento para resistência a doenças. In: DIAS. L. A. S. (Org.). Melhoramento genético do cacaueiro. Viçosa: FUNAPE, 2001. v. 1, p. 289-324.

YONEYAMA, S.; NUNES, A.M.L.; DUARTE, M.L.R.; SHIMIZU, O.; ENDO, T.; ALBUQUERQUE, F.C. Controle químico da vassoura-de-bruxa em cupuaçuzeiro. In: SEMINÁRIO INTERNACIONAL SOBRE PIMENTA-DO-REINO E CUPUAÇU, 1., 1996, Belém. Anais... Belém: EMBRAPA, CPATU/JICA, 1997. p.161-172.
VENTURIERI, G.A. Cupuaçu: a espécie, sua cultura, usos e processamento. Belém: Clube do Cupu, 1993. 108p. 